\title{
Effect of Material Property on the Springback in Stamping of High Strength Steel
}

\author{
Wenyu Ma, Jianwei Yang, Jun Zhang, Xuebin Zheng, and Chunguang Li
}

\begin{abstract}
The effect of material property on the springback of part in stamping process is significant. And it is necessary to study the influence. Traditionally, the material property indices concerned are tensile strain hardening exponent (r), Plastic strain ratio (n), and yield stress. In this study, the effect of tensile strain hardening exponent (r), plastic strain ratio (n) and yield stress on the springback was studied with the help of the design of test, FE analysis, Response surface analysis. The springback increases with the increase of $n$ value and yield stress. And $r$ value shows a slight effect.
\end{abstract}

Index Terms-Springback, material property, high strength steel.

\section{INTRODUCTION}

The high strength steel becomes more and more popular in recent years. Wang et al. [1] used theory, simulation and experiment to study the material property and formability. Three-point bending and other methods were also employed.

Springback is an obvious defect in the application of high strength steel. Much effort has devoted to the analysis of springback. Ingarao et al. [2] analyzed the relationship between the springback and forming factors. The compromise between springback and thinning is also studied. And the multi-objective solution is employed to solve the conflict between different indexes. A. Ghaei et al. [3] studied the springback of high strength steel and the nonlinear elastic loading-unloading-reloading is considered in this paper. The simulation software used is ABAQUS. The simulated result was also compared with experimental one, and good correlation is shown. Chongthairungruang et al. [4] analyzed the springback effect in terms of the high strength steel using FE simulation and experiment. The model for elastic modulus change is also established and the microstructure is also investigated. The pre-strain effect is also considered and different material models are also considered. Sumikawa et al [5] improved the springback prediction accuracy in consideration of nonlinear elastoplastic behavior. The Yoshida-Uemori model and proposed model were used, and comparison between model-predicted results and experimental ones was conducted. The response surface analysis is an effective method in research analysis and also employed in other papers [6], [7].

Manuscript received May 30, 2018; revised September 3, 2018.

The authors are with Research Institute of Technology of Shougang Group Co., Ltd., Beijing, China (e-mail: wymaustb@163.com, dr.yangjianwei@gmail.com, zhengxb@shougang.com.cn, lichunguang@shougang.com.cn).
The material property affects the formability including springback significantly. So it is necessary to analyze the relationship between the springback and material properties. The material properties concerned in the material formability are tensile strain hardening exponent (r), Plastic strain ratio (n), and yield stress. And these three properties are treated as important factors.

In this study, a FE model of traditional S-shaped U-channel was established. This model of S-shape U-channel can be used to capture the springback variation. The effect of material property on the springback was analyzed with the help of finite element analysis method, response surface analysis. Then the conclusion for the effect of material property on the springback was achieved.

\section{THE DESIGN OF TEST}

The $\mathrm{n}$ is the symbol of tensile strain hardening exponent, the larger the $\mathrm{n}$ value is, the better. It indicates a good formability. The $\mathrm{r}$ is the symbol of plastic strain ratio. It is the ratio of strain in width against the strain in thickness direction. A large $r$ value indicates that the thinning is weak and the formability is good. The y is the symbol for the yield stress. The yield stress can also reflect the formability. And the high yield stress indicates the material has a hard property. Generally, the material is expected to get high strength and good formability. And the yield strength affects the springback of the part significantly.

The experiment design method Box-Behnken was used to design the tests. The number of the tests is 13 . There are three design variables, namely tensile strain hardening exponent (r), Plastic strain ratio (n), and yield stress. Each factor has three levels. The levels of tensile strain hardening exponent (r) are $0.8,1.1$ and 1.4. The levels of plastic strain ratio (n) are 0.14 , 0.16 and 0.18 . The levels of yield stress (y) are 350, 375 and $400 \mathrm{MPa}$. The design of tests is shown in the following table.

After the FE simulation, the value of springback is measured. And the springback of the corner is the maximum and recorded and listed in the following table. The total thirteen tests were run, and the corresponding value of springback can be calculated after the springback step.

\section{FE MODEL}

The FE model includes four main parts. They are punch, die, blank and blank holder. The punch, die and blank holder are rigid, and the blank can be deformed into a targeted shape (see Fig. 1). 


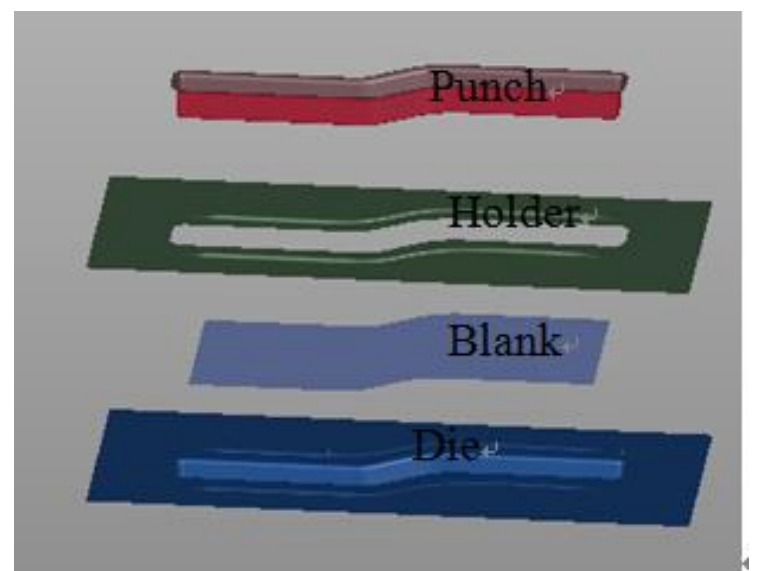

Fig. 1. FE model for stamping and springback.

\section{ANALYSIS AND DISCUSSION}

The FE software was used to analyze the effect of these material property parameters on the springback. The FE model is a typical S-shaped U channel, and the figure is a formed one with springback value distribution. The maximum springback value is located at the right corner. The maximum springback value can be recorded and listed in the table. Then the following analysis can be conducted (see Fig. 2) .

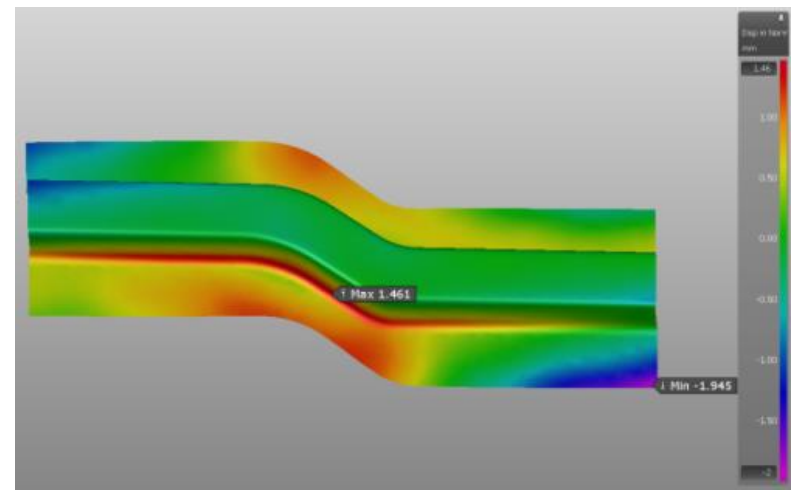

Fig. 2. The springback distribution for the formed S-shaped U-channel after springback process.

\section{RESULTS AND DISCUSSION}

The figure shows the relationship between the springback value and material characters, including $r$ value and $n$ value (see Fig. 3).

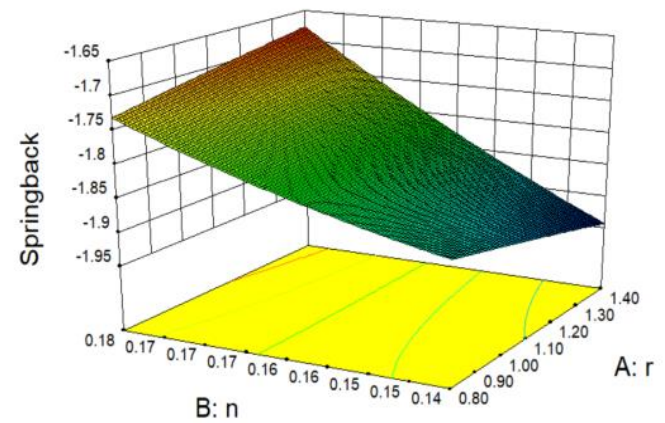

Fig. 3. The response surface for the effect of $r$ value and $n$ value on the springback.

It is shown in the figure that the springback increases with the increase of $n$ value. However, the $r$ value shows slight effect on the springback.

The relationship between the springback and material properties, including $r$ value and yield stress is given in the following figure (see Fig. 4).

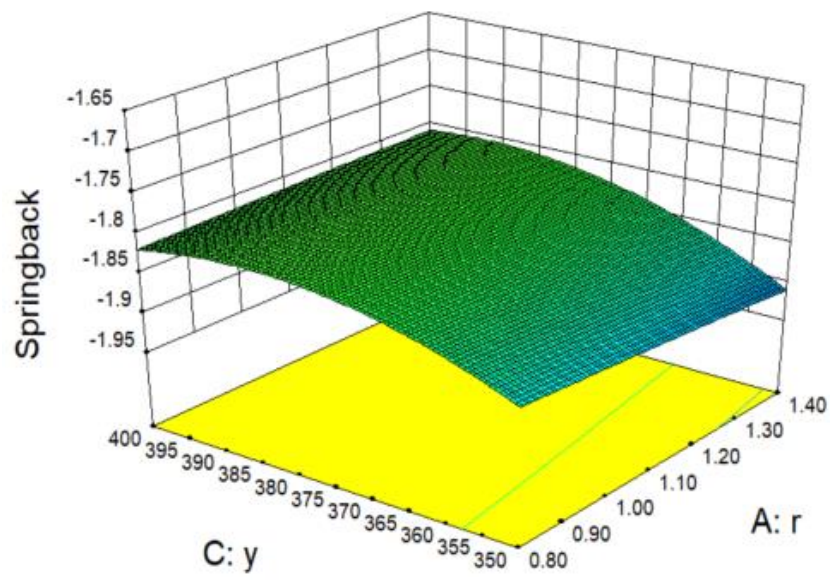

Fig. 4. The response surface for the effect of $r$ value and yield stress on the springback.

It can be seen from the figure that the springback increases with increasing the yield stress, and the springback has insignificant relationship with the $r$ value.

The relationship between the springback and material properties, including yield stress and $\mathrm{n}$ value can be achieved and analyzed. The related 3-D figure is given in the follows (see Fig. 5).

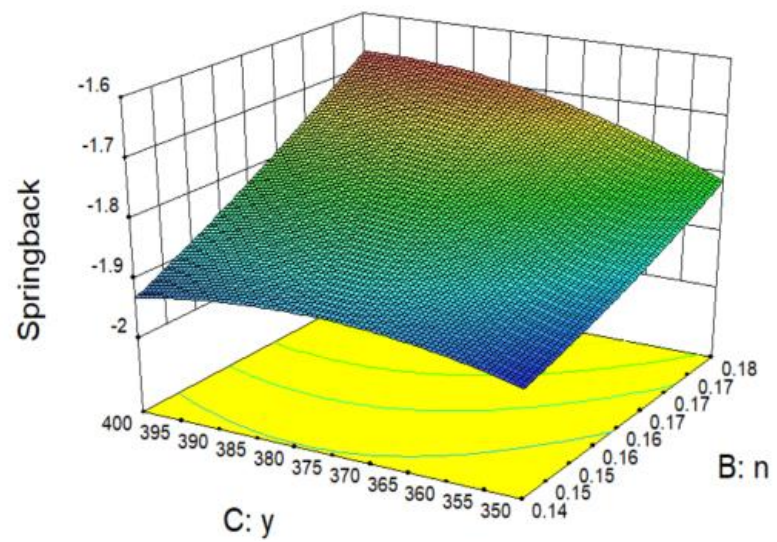

Fig. 5. The response surface for the effect of $n$ value and yield stress on the springback.

The above figure shows the relationship between the springback and $n$ value and yield stress value. The springback value increases with the increase of $n$ value. When the $n$ value is large, the springback increases with the increase of yield stress, and when the $\mathrm{n}$ value is small, the effect of yield stress shows tiny effect on the springback. Generally, the springback increases with the increase of $n$ value with the yield stress range of $350 \mathrm{MPa}$ to $400 \mathrm{MPa}$.

In the data analysis software, the effect of one factor in the springback can be got. In the one factor analysis part, the $r$ value shows a slight effect on the springback. And the $n$ value affects the springback significantly, the springback increases significantly with the increase of $n$ value. And with the 
increase of yield stress, the springback increases. In the figure, $\quad y$ is short for yield stress.

TABLE I: THE TEST DESIGN AND THE CORRESPONDING RESULTS

\begin{tabular}{|c|c|c|c|c|}
\hline Run & A: $\mathrm{r}_{\mathrm{m}}$ & B:n & C:y & -1.823 \\
\hline 1 & 0.8 & 0.16 & 400 & -1.728 \\
\hline 2 & 0.8 & 0.18 & 375 & -1.864 \\
\hline 3 & 0.8 & 0.16 & 350 & -1.876 \\
\hline 4 & 0.8 & 0.14 & 375 & -1.916 \\
\hline 5 & 1.1 & 0.14 & 400 & -1.825 \\
\hline 6 & 1.1 & 0.18 & 350 & -1.814 \\
\hline 7 & 1.1 & 0.16 & 375 & -1.953 \\
\hline 8 & 1.1 & 0.14 & 350 & -1.667 \\
\hline 9 & 1.1 & 0.18 & 400 & -1.667 \\
\hline 10 & 1.4 & 0.18 & 375 & -1.904 \\
\hline 11 & 1.4 & 0.16 & 350 & -1.820 \\
\hline 12 & 1.4 & 0.16 & 400 & -1.945 \\
\hline 13 & 1.4 & 0.14 & 375 & \\
\hline
\end{tabular}

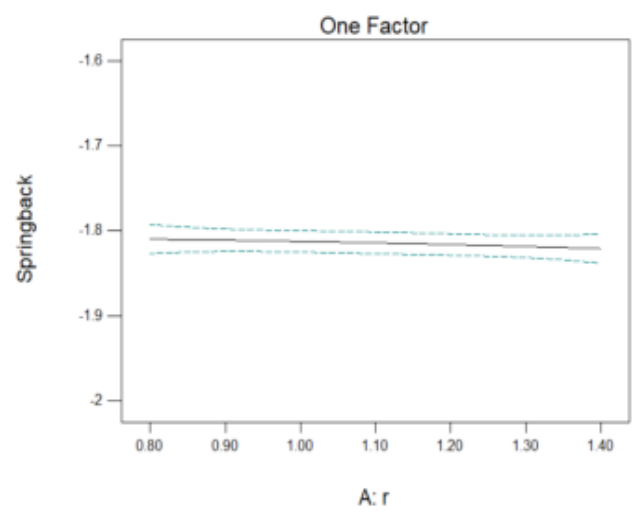

(a)

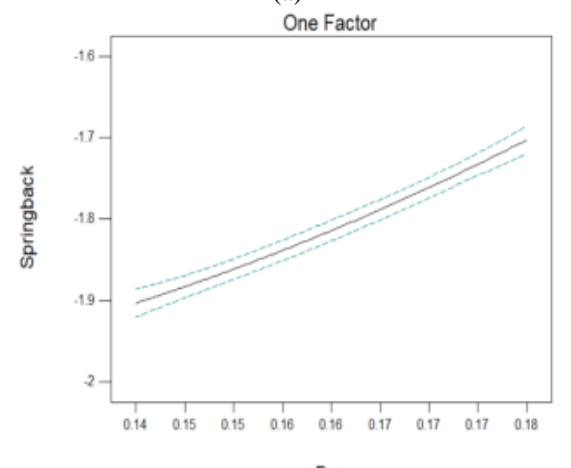

(b)

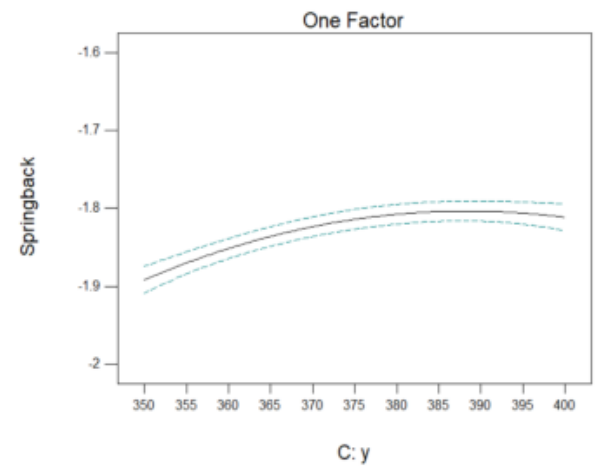

(c)

Fig. 6. the effect of $r$ value (a), $n$ value (b) and yield stress (c) on the springback for one factor effect.

\section{CONCLUSION}

In this study, a FE model of S-shaped U-channel is established and applied to analyze the effect of material properties on the springback. The relationship between springback and material properties (yield stress, $r$ value and $n$ value) can be got. Generally, the springback increases with the increase of the yield stress, the increase of $n$ value. And the $r$ value shows slight effect on the springback.

\section{ACKNOWLEDGMENT}

The authors are grateful to Professor Jianguo Lin, Royal Academy of Engineering and Department of Mechanical Engineering, Imperial College, UK for the guidance and help. The authors also thank Professor Baoyu Wang from university of science and technology Beijing, very much for the guideline and help.

\section{REFERENCES}

[1] J. Wang, S. Afshan, M. Gkantou, M. Theofanous, C. Baniotopoulos, and L. Gardner, "Flexural behaviour of hot-finished high strength steel square and rectangular hollow sections," Journal of Constructional Steel Research, vol. 121, pp. 97-109, 2016.

[2] G. Ingarao, R. D. Lorenzo, and F. Micari, "Analysis of stamping performances of dual phase steels: A multi-objective approach to reduce springback and thinning failure," Materials and Design, vol. 30, pp. 4421-4433, 2009.

[3] A. Ghaei, D. E. Green, and A. Aryanpour, "Springback simulation of advanced high strength steels considering nonlinear elastic unloading — Reloading behavior," Materials and Design, vol. 88, pp. 461-470, 2015.

[4] B. Chongthairungruang, V. Uthaisangsuk, S. Suranuntchai, and S. Jirathearanat, "Experimental and numerical investigation of springback effect for advanced high strength dual phase steel," Materials and Design, vol. 39, pp. 318-328, 2012.

[5] S. Sumikawa, A. Ishiwatari, and J. Hiramoto, "Improvement of springback prediction accuracy by considering nonlinear elastoplastic behavior after stress reversal," Journal of Materials Processing Technology, vol. 241, pp. 46-53.2017.

[6] W. Y. Ma, B. Y. Wang, J. H. Bian, X. F. Tang, L. Yang, and Y. M. Huo, "A new damage constitutive model for thermal deformation of 
AA6111 sheet," Metallurgical and Materials Transactions A, vol. 46, no. 6, pp. 2748-2757.

[7] W. Y. Ma, B. Y. Wang, X. F. Tang, W. C. Xiao, and J. Zhou, "Influence of solution heat treatment on mechanical response and fracture behaviour of aluminium alloy sheet an experimental study," Materials and Design, 2015, vol. 88, pp. 1119-1126.

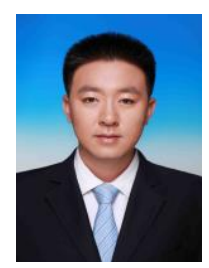

Wenyu Ma was born in June 1988 in Liaoning province. He graduated from University of Science and Technology Beijing in 2016 and got a doctoral degree. The major field of study is mechanical engineering.

He worked in research Institute of Technology of Shougang Group Co., Ltd. from August 2016 after graduation until now in Beijing, China. 